Check for updates

Cite this: Chem. Sci., 2019, 10, 2998

๑ All publication charges for this article have been paid for by the Royal Society of Chemistry

\section{The fate of bromine after temperature-induced dehydrogenation of on-surface synthesized bisheptahelicene $\uparrow$}

\author{
Anaïs Mairena, (D) a Milos Baljozovic, (D) a Maciej Kawecki, (D) ${ }^{a}$ Konstantin Grenader, ${ }^{b}$ \\ Martin Wienke, ${ }^{\mathrm{c}}$ Kévin Martin, ${ }^{\mathrm{d}}$ Laetitia Bernard, ${ }^{a}$ Narcis Avarvari, (D) d \\ Andreas Terfort, (DD ${ }^{\mathrm{b}}$ Karl-Heinz Ernst (D)*ae and Christian Wäckerlin (D) *a
}

\begin{abstract}
The on-surface synthesis of bisheptahelicene by Ullmann coupling of 9-bromoheptahelicene on Au(111) and its temperature-induced dehydrogenation is studied using temperature-programmed reaction spectroscopy and time-of-flight secondary ion mass spectrometry. Specific dehydrogenation products of bisheptahelicene after loss of 6,8 and 10 hydrogen atoms are identified, corresponding to molecules having undergone Diels-Alder transformations and intramolecular $\mathrm{C}-\mathrm{C}$ coupling reactions. By combining with atomic hydrogen produced by dehydrogenation, the Ullmann coupling side-product bromine desorbs as $\mathrm{HBr}$. $\mathrm{H}_{2}$ desorption emerges only after all $\mathrm{Br}$ has desorbed. Such characteristic behavior is explained by a kinetic model which explicitly considers the coverage of transient atomic $\mathrm{H}$ on the surface. Heating experiments performed with saturated layers of different $\mathrm{Br}$-containing molecules reveal that the onset of $\mathrm{HBr}$ desorption depends strictly on the dehydrogenation step and therefore on the structure of the molecules.
\end{abstract}

Received 23rd October 2018

Accepted 15th January 2019

DOI: $10.1039 / \mathrm{c} 8 \mathrm{sc} 04720 \mathrm{k}$

rsc.li/chemical-science

\section{Introduction}

A very broad range of oligomers, $1 \mathrm{D}$ and $2 \mathrm{D}$ polymers can be obtained reliably and predictably by Ullmann coupling on surfaces. $^{1-6}$ The halogen atom (typically $\mathrm{Br}$ or I) remains adsorbed on the surface as side-product after the reaction. In a second step, the on-surface synthesized hydrocarbon products can be modified by intra- or intermolecular dehydrogenation. ${ }^{6-12}$ Depending on the structural changes induced by this second dehydrogenation step it may be very difficult to identify the reaction products with common surface analytical methods. In situ time-of-flight secondary ion mass spectrometry (ToFSIMS) is a very valuable tool to precisely identify reaction products, but has been rarely applied to unravel on-surface chemistry. In combination with temperature-programmed reaction spectroscopy (TPRS), volatile desorption products as well as the remaining adsorbates can be analysed using mass

${ }^{a}$ Empa, Swiss Federal Laboratories for Materials Science and Technology, 8600 Dübendorf, Switzerland. E-mail: christian.waeckerlin@empa.ch; karl-heinz.ernst@ empa.ch

${ }^{b}$ Department of Chemistry, Institute of Inorganic and Analytical Chemistry, GoetheUniversity, 60438 Frankfurt, Germany

${ }^{c}$ Department of Chemistry, University of Hamburg, 20146 Hamburg, Germany ${ }^{d}$ Laboratoire Moltech-Anjou, CNRS-Université d'Angers, 49045 Angers, France ${ }^{e}$ Department of Chemistry, University of Zurich, 8057 Zurich, Switzerland

$\dagger$ Electronic supplementary information (ESI) available. See DOI: $10.1039 / \mathrm{c} 8 \mathrm{sc} 04720 \mathrm{k}$ spectrometry, thus providing deeper insight into the reaction landscape.

Because of its low barrier for recombinative desorption on $\mathrm{Cu}$, $\mathrm{Ag}$ and $\mathrm{Au},{ }^{13}$ it is expected that the adsorbed atomic hydrogen desorbs immediately after dehydrogenation and is therefore an irrelevant side-product. However, recent work showed that atomic hydrogen produced by on-surface chemistry, such as dehydrogenation or metalation-induced dehydrogenation, may react with other species instead of desorbing. ${ }^{14-20}$ Recently, desorption of $\mathrm{HBr}$ during cyclodehydrogenation of polymerized 10,10'-dibromo-9,9'-bianthryl (DBBA) on $\mathrm{Au}(111)^{14}$ and of polymerized 1,6-dibromopyrene on $\mathrm{Ag}(110)^{19}$ has been reported. It has been shown that $\mathrm{Br}$ and I, initially bound to the otherwise identical precursor, leave the surface at the same temperature. ${ }^{20}$ The kinetics of this important reaction in Ullmann-chemistry based on-surface synthesis is not entirely understood. The true desorption temperature of pure $\mathrm{Br} / \mathrm{Au}(111)$ is unknown and the reason for the large variations in the reported temperatures (500 to $633 \mathrm{~K}$ ) for $\mathrm{Br}$ desorption from $\mathrm{Au}(111)$ in presence of different hydrocarbons ${ }^{20-25}$ remains unclear.

Here, the Ullmann coupling of 9-bromoheptahelicene $(\mathrm{Br}[7] \mathrm{H})$ to bisheptahelicene $(\mathrm{bis}[7] \mathrm{H})$ on $\mathrm{Au}(111)$ in ultrahigh vacuum and the following temperature-induced cyclodehydrogenation of bis[7]H (Fig. 1) are studied using TPRS and ToF-SIMS. For comparison, the dehydrogenation chemistry is also studied for solution-synthesized bis[7] $\mathrm{H}$ deposited onto the gold surface. A simple kinetic model, which explicitly considers the coverage of transiently existing atomic $\mathrm{H}$, is introduced to explain 


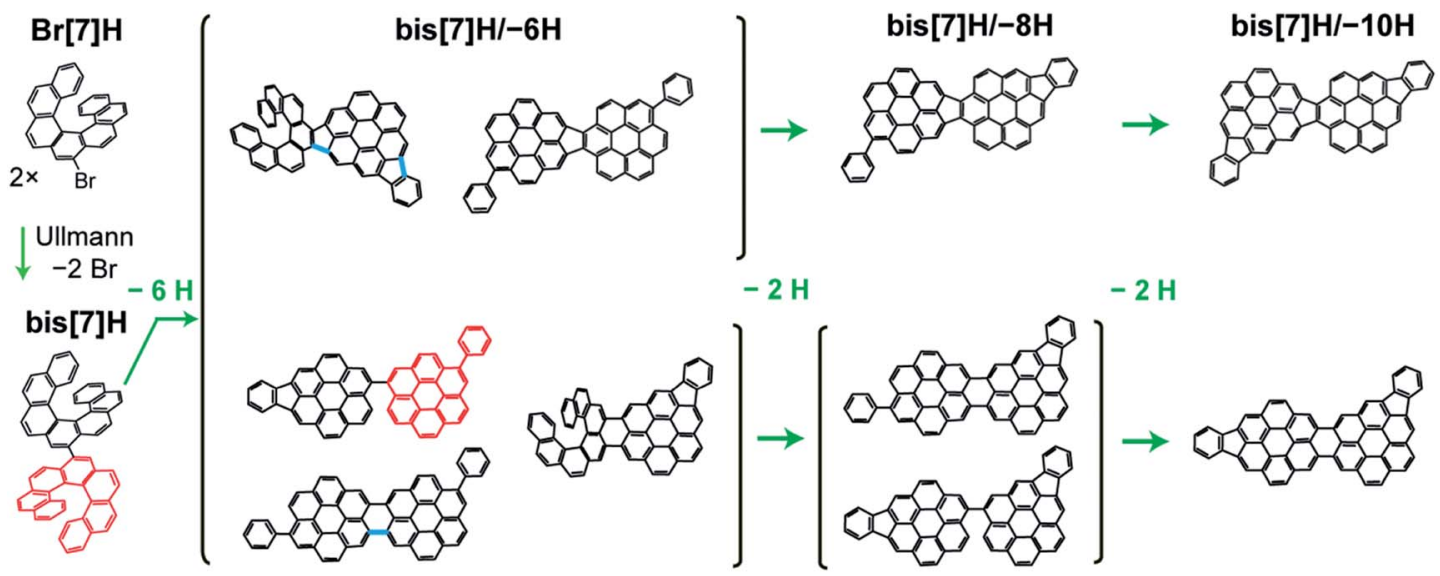

Fig. 1 Potential reaction pathways for dehydrogenation of bis[7]H after Ullmann coupling of $\mathrm{Br}[7] \mathrm{H}$. A subset of stereomers is shown to illustrate potential reaction products in the dehydrogenation process due to steric overcrowding. A Diels-Alder reaction causes the transformation of a [7] $\mathrm{H}$ into a phenylcoronene subunit (exemplified in red, loss of $2 \mathrm{H}$ per [7] $\mathrm{H}$ unit). Cyclodehydrogenation between the helicenes and at the phenylcoronene creates new $\mathrm{C}-\mathrm{C}$ bonds, resulting in indenocoronene subunits or new 5 - or 6 -membered rings (loss of $2 \mathrm{H}$ atoms per new $\mathrm{C}-\mathrm{C}$ bond). Some of these new bonds are illustrated in blue. Different combinations of the aforementioned processes lead to the loss of 2, 4, 6, 8 and $10 \mathrm{H}$ atoms. Experimentally, isomers having lost 6, 8 and $10 \mathrm{H}$ atoms are identified.

$\mathrm{HBr}$ and $\mathrm{H}_{2}$ desorption spectra. The different desorption temperatures of $\mathrm{Br}$ as $\mathrm{HBr}$ of different molecules are compared and are shown to be significantly lower than the desorption temperature of $\mathrm{Br}$ from $\mathrm{Au}(111)$ in the absence of molecules.

\section{Experimental}

The samples are prepared in ultra-high vacuum by $\mathrm{Ar}^{+}$sputtering and annealing of $\mathrm{Au}(111)$ followed by the sublimation of respective molecules and analysed in situ by TPRS and ToFSIMS. The sample temperature is measured by a thermocouple directly attached to the crystal. The heating is performed resistively (ToF-SIMS) and by electron-beam bombardment (TPRS) to the backside of the sample holder.

\section{TPRS measurements}

TPRS is measured using a quadrupole mass spectrometer (Balzers QME 200) after preparing the samples in situ. The base pressure was better than $10^{-9}$ mbar. The MS signal recorded before starting the temperature ramp, which corresponds to the partial base pressure, is subtracted.

\section{ToF-SIMS measurements}

ToF-SIMS (IONTOF ToF-SIMS 5) is performed with a beam of 25 $\mathrm{keV} \mathrm{Bi}_{3}{ }^{+}$used as primary ions. The spectra were acquired by randomly rastering the beam of $\mathrm{Bi}_{3}{ }^{+}$ion pulses over the area of $500 \times 500 \mu \mathrm{m}^{2}$. An extraction voltage of $3 \mathrm{kV}$ was used. The total dose density is kept below $10^{12}$ ions per $\mathrm{cm}^{2}$, i.e. in the static limit. A new spot on the sample is analysed for each annealing step. 100 scans in each polarization (positive and negative) were collected at the same spot. The spectra obtained within those 100 scans were identical to the first and last 10 scans (Fig. S3 $\dagger$ ), evidencing that the detected signals are not affected by the $\mathrm{Bi}_{3}{ }^{+}$ bombardment. The pressure in the chamber during preparation and measurements was below $10^{-8}$ mbar.

\section{Deposition of $\mathrm{Br}$}

$\mathrm{Br}$ is deposited by annealing $\mathrm{AuBr}_{3}$ in a quartz crucible to $373 \mathrm{~K}$ while the $\mathrm{Au}(111)$ substrate is kept at $473 \mathrm{~K}$. No $\mathrm{Au}$ is detected with XPS after deposition on $\mathrm{Cu}(111)$ kept at room temperature. Thus we conclude that $\mathrm{AuBr}_{3}$ decomposes and releases $\mathrm{Br}_{2}$ or Br. Deposition on $\mathrm{Au}(111)$ kept at $473 \mathrm{~K}$ for 3 min results in a very similar Br coverage (detected by XPS, Fig. S1†) as in case of $1 \mathrm{ML}$ of $\mathrm{Br}[7] \mathrm{H}$. Deposition on the sample kept at room temperature leads to much higher Br coverages. As shown in ref. 29 and 30, the high coverage phases have lower desorption temperatures than the low coverage phase shown in Fig. 2a.

\section{Deposition of molecules}

The molecules are deposited by sublimation onto the sample kept at room temperature. $1 \mathrm{ML}$ refers to a saturated layer. For $\mathrm{Br}[7] \mathrm{H}$ (9-bromoheptahelicene) and $\operatorname{Br}[4] \mathrm{H}$ (2-bromotetrahelicene), $1 \mathrm{ML}$ is obtained by desorption of the multilayer by annealing to $373 \mathrm{~K}$ and $413 \mathrm{~K}$ respectively. The coverage of bis[7] $\mathrm{H}$ (bisheptahelicene) and $\operatorname{diBr}[4] \mathrm{H}$ (2,3-dibromo[4]helicene) is defined by comparing the $\mathrm{C} 1 \mathrm{~s} \mathrm{XP}$ signal with $1 \mathrm{ML}$ of $\mathrm{Br}[7] \mathrm{H}$ and $\mathrm{Br}[4] \mathrm{H}$, respectively. In the case of $\mathrm{BrP}$ (1-bromopyrene), the adsorption of molecules beyond the first layer is self-limiting at room temperature. The corresponding C 1s XP spectra are shown in Fig. S2.†

\section{Synthesis}

$\mathrm{Br}[7] \mathrm{H}$, bis[7] $\mathrm{H}, \mathrm{Br}[4] \mathrm{H}$ and $\operatorname{diBr}[4] \mathrm{H}$ were synthesized according to the literature. ${ }^{26-28}$ DBBA and BrP were purchased from Sigma-Aldrich.

\section{Results and discussion}

\section{$\mathrm{H}_{2}$ and $\mathrm{HBr}$ desorption}

Fig. 2 shows TPR spectra of saturated monolayers of bis[7] $\mathrm{H}$ and $\mathrm{Br}[7] \mathrm{H}$ on $\mathrm{Au}(111)$ as well as of a submonolayer of $\mathrm{Br}$ equivalent 

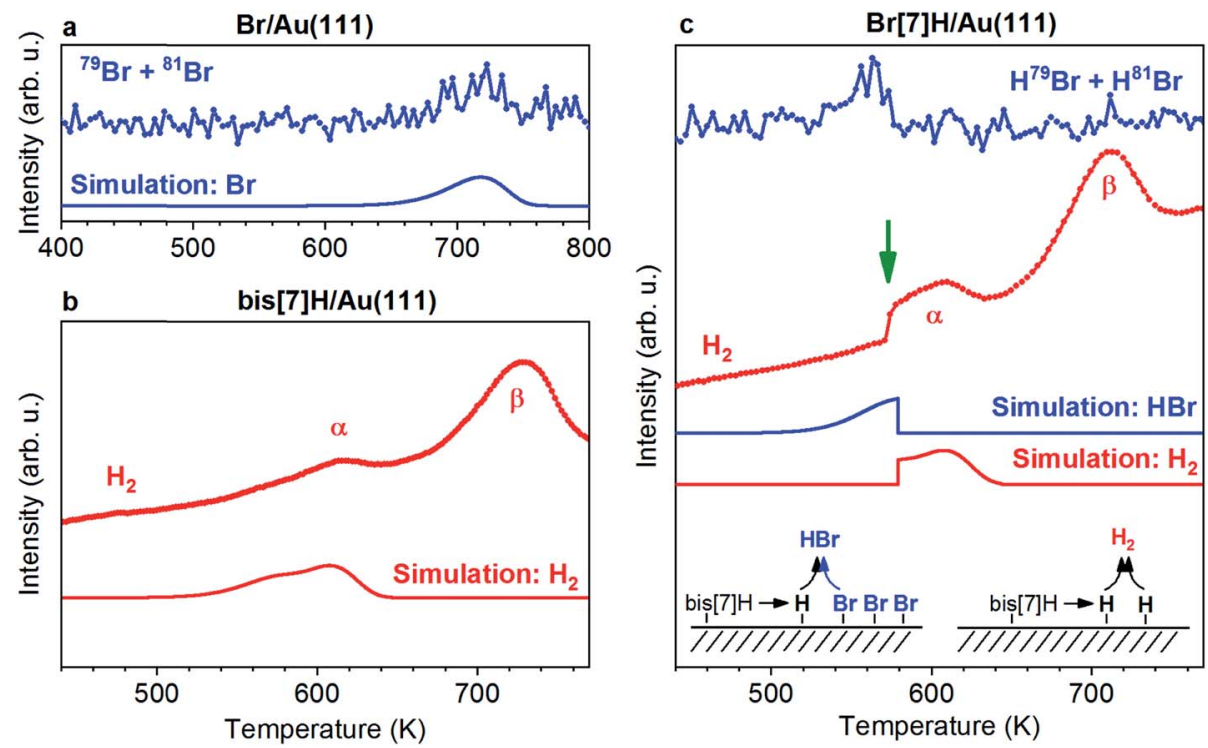

Fig. 2 Experimental and simulated TPR spectra of adsorbates on $\mathrm{Au}(111)$. (a) Br TPR spectra of $\mathrm{Br} / \mathrm{Au}(111)$. In the absence of other species, Br desorbs at $720 \mathrm{~K}$. (b) $\mathrm{H}_{2}$ TPR spectra of $0.87 \mathrm{ML}$ bis[7]H/Au(111). Two peaks are observed; $\alpha$ corresponds to cyclodehydrogenation/Diels-Alder cycloaddition including dehydrogenation and $\beta$ to further non-specific dehydrogenation. Only the relevant peak $\alpha$ is modelled. (c) Br and $\mathrm{H}_{2} \mathrm{TPR}$ spectra of $1 \mathrm{ML} \mathrm{Br}[7] \mathrm{H} / \mathrm{Au}(111)$. Simulations considering competing desorption of hydrogen as $\mathrm{H}_{2}$ and $\mathrm{HBr}$ reproduce the step like feature (green arrow). The heating rate is $3 \mathrm{~K} \mathrm{~s}^{-1}$.

to the amount of $\mathrm{Br}$ present in a saturated layer of $\mathrm{Br}[7] \mathrm{H}$. In the absence of molecules, $\mathrm{Br}$ desorbs at $720 \mathrm{~K}$ (Fig. 2a). No $\mathrm{HBr}$ signal is detected. In view of the desorption of $\mathrm{Cl}, \mathrm{Br}$ and I from $\mathrm{Ag}$ and $\mathrm{Cu}$ surfaces as metalhalides, ${ }^{29-31}$ and the proposed likely desorption I on $\mathrm{Au}(111)$ as $\mathrm{AuI},{ }^{20}$ desorption as AuBr should be considered. If this is the case, the detected $\mathrm{Br}$ signal is due to fragmentation in the mass spectrometer. Unfortunately, the high mass of AuBr does not allow for its detection by our instrumentation. In the simple picture of first order kinetics and assuming a pre-exponential factor of $10^{13} \mathrm{~Hz}$, an activation energy for desorption of $192 \mathrm{~kJ} \mathrm{~mol}^{-1}$ is derived (Fig. 2a, see also ESI $\dagger$ ). This value is significantly lower than the adsorption energies of $\mathrm{Br}\left(270 \mathrm{~kJ} \mathrm{~mol}^{-1}\right)$ and $\mathrm{Br}_{2}\left(296 \mathrm{~kJ} \mathrm{~mol}^{-1}\right)$ on $\mathrm{Au}(111)$ calculated by $\mathrm{DFT},{ }^{32}$ indicating that $\mathrm{Br}$ desorbs indeed as $\mathrm{AuBr}$.

In the $\mathrm{H}_{2}$ TPR spectrum of bis[7]H (Fig. 2b), two peak maxima $\alpha$ and $\beta$ are observed. The continuously rising $\mathrm{H}_{2}$ background is due to a general warming up of the sample holder. Signal $\alpha$ is identified as dehydrogenation due to steric overcrowding, in accordance with the literature ${ }^{\mathbf{6 , 1 4 , 1 8}}$ and with the ToF-SIMS results reported below. Peak $\beta$ corresponds to non-specific dehydrogenation. ${ }^{18,33}$

The $\mathrm{H}_{2}$ TPR spectrum obtained for $1 \mathrm{ML} \mathrm{Br}[7] \mathrm{H}$ (Fig. 2c) is very similar to the one for bis[7] $\mathrm{H}$, with the exception that the first part of peak $\alpha$ is missing and that the $\mathrm{H}_{2}$ desorption rate rises suddenly at $574 \mathrm{~K}$ (green arrow). The $\mathrm{HBr}$ desorption rate peaks at $563 \mathrm{~K}$ and drops to zero at $574 \mathrm{~K}$. This desorption temperature of $\mathrm{Br}$ in the presence of [7]helicenes is $160 \mathrm{~K}$ lower than for $\mathrm{Br}$ in absence of molecules. ToF-SIMS shows complete coupling of $\mathrm{Br}[7] \mathrm{H}$ to bis[7] $\mathrm{H}$ after annealing to $457 \mathrm{~K}$ (Fig. 3). Hence, $\mathrm{Br}[7] \mathrm{H}$ has already undergone Ullmann coupling in the temperature range of peak $\alpha$. The conspicuous step in the $\mathrm{H}_{2}$ TPRS trace and formation of $\mathrm{HBr}$ before onset of $\mathrm{H}_{2}$ evolution strongly suggests that $\mathrm{HBr}$ desorption is induced by the dehydrogenation of bis[7]H. Consequently, depletion of $\mathrm{Br}$ from the $\mathrm{Au}$ surface goes hand in hand with dehydrogenation of the hydrocarbons.

\section{Dehydrogenation products identified by SIMS}

The chemical transformation of $\mathrm{Br}[7] \mathrm{H}$ on the basis of the ToFSIMS data is shown in Fig. 3. It displays ToF-SIMS spectra taken from a multilayer of $\mathrm{Br}[7] \mathrm{H} / \mathrm{Au}(111)$ annealed sequentially to different temperatures. The full sequence is shown in Fig. S4. $\dagger$ $\mathrm{Br}^{-}$ions (Fig. 3a), $\mathrm{C}_{30} \mathrm{H}_{17} \mathrm{Br}^{+}$ions (Fig. 3b) and $\mathrm{C}_{60} \mathrm{H}_{\{34,28,26,24\}}{ }^{+}$ ions (Fig. 3c) are indicative for $\mathrm{Br}, \mathrm{Br}[7] \mathrm{H}$, bis[7] $\mathrm{H}$ and its dehydrogenation products, respectively. Annealing to $404 \mathrm{~K}$ leads to desorption of molecules from the second layer (Fig. S4 $\dagger$ ). In particular for the assignment of the bis[7]H-related signals the characteristic mass distribution, due to ${ }^{13} \mathrm{C}$, allows for an unambiguous identification (indicated as bars in Fig. 3ac). The presence of a bis[7] $\mathrm{H}$ signal after annealing to $404 \mathrm{~K}$ indicates that some of the $\mathrm{Br}[7] \mathrm{H}$ molecules have already undergone Ullmann coupling (Fig. 3c). Annealing to $457 \mathrm{~K}$ leads to the disappearance of the $\mathrm{Br}[7] \mathrm{H}$-based signals, evidencing complete debromination and Ullmann coupling (Fig. 3b).

This observation is consistent with coupling temperatures (380 to $473 \mathrm{~K}$ ) reported for other brominated molecules on $\mathrm{Au}(111)^{4,34-36}$ The remaining signals correspond to the SIMSinduced fragmentation pattern of bis[7]H, spreading over a large mass range below its main peak. For example, after complete coupling of $\mathrm{Br}[7] \mathrm{H}$ at $457 \mathrm{~K}$, the intensity at the main peak of $\mathrm{Br}[7] \mathrm{H}$ due to fragmentation is $9.5 \%$ of the $\operatorname{bis}[7] \mathrm{H}$ signal (Fig. S4c $\dagger$ ). Therefore, in Fig. 3e, which shows the integrated intensity of the main peak of $\mathrm{Br}[7] \mathrm{H}$ as a function of 

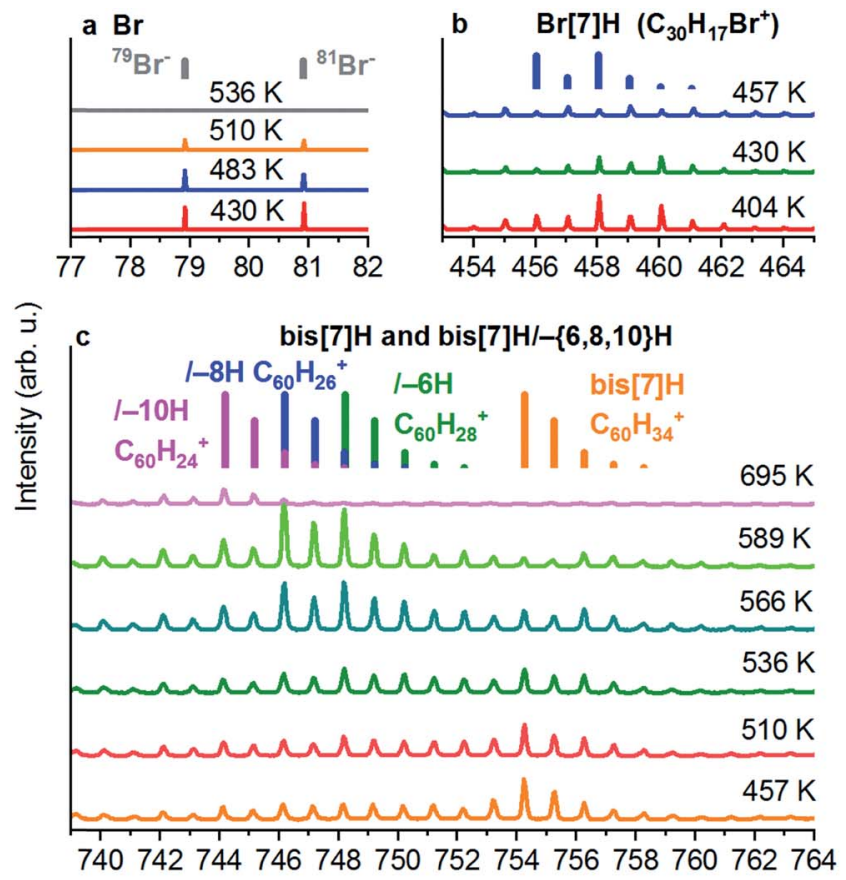

Mass (u)

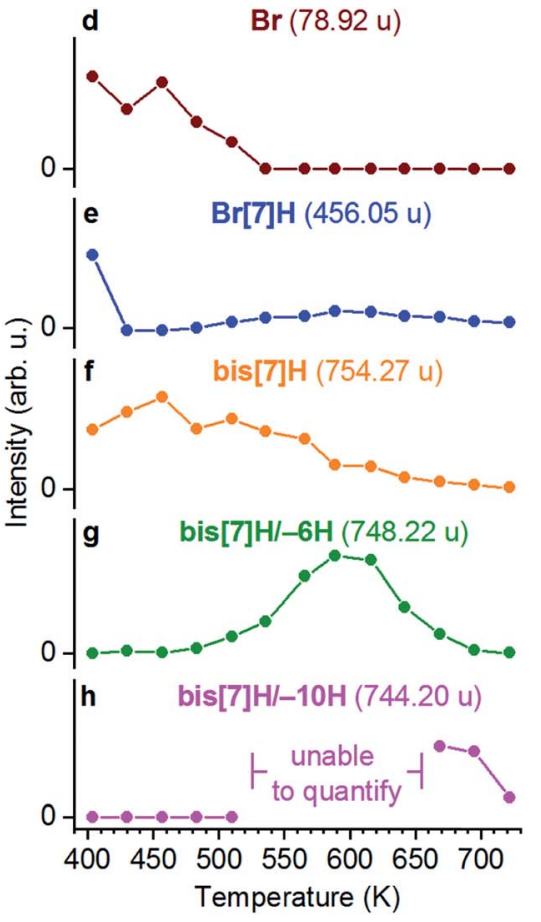

Fig. 3 ToF-SIMS analysis of a saturated layer of $\mathrm{Br}[7] \mathrm{H}$ on $\mathrm{Au}(111)$. The saturated layer was obtained by desorption of excess molecules from a multilayer by annealing to $404 \mathrm{~K}$. (a) $\mathrm{Br}^{-}$, (b) $\mathrm{Br}[7] \mathrm{H}\left(\mathrm{C}_{30} \mathrm{H}_{17} \mathrm{Br}^{+}\right)$and (c) $\mathrm{C}_{60} \mathrm{H}_{\{34,28,26,24\}}{ }^{+}$corresponding to bis[7] $\mathrm{H} /-\{6,8,10\} \mathrm{H}$ signals. The mass distributions of $\mathrm{C}_{60} \mathrm{H}_{\{34,28,26,24\}}{ }^{+}$are shown as coloured bars. Integrated intensities of the main peak of (d) $\mathrm{Br}$, (e) $\mathrm{Br}[7] \mathrm{H}$, (f) bis[7] H, (g) bis[7] H/-6H and $(\mathrm{h})$ bis $[7] \mathrm{H} /-10 \mathrm{H}$. Annealing to $404 \mathrm{~K}$ already induces partial Ullmann coupling to bis[7] $\mathrm{H}$ (e). Ullmann coupling is complete after annealing to $457 \mathrm{~K}(\mathrm{e})$. The onset of dehydrogenation occurs after annealing to $510 \mathrm{~K}(\mathrm{~g})$ and coincides with the vanishing Br signal (d). The intensity of bis[7] $\mathrm{H} /-6 \mathrm{H}$ (and bis[7] $\mathrm{H} /-8 \mathrm{H}$ which is not quantified) reaches its maximum at $589 \mathrm{~K}$. After annealing to $695 \mathrm{~K}$, only bis[7] $\mathrm{H} /-10 \mathrm{H}$ is detected.

temperature, $9.5 \%$ of the intensity of the bis[7] $\mathrm{H}$ signal is subtracted. Partial $\mathrm{Br}$ desorption occurs after annealing to $510 \mathrm{~K}$ and is complete after annealing to $536 \mathrm{~K}$. In addition, starting from $510 \mathrm{~K}$, the signals in the bis[7] $\mathrm{H}$ mass range shift towards lower masses (Fig. 3c). In particular $\mathrm{C}_{60} \mathrm{H}_{28}{ }^{+}$(bis[7] $\mathrm{H} /-6 \mathrm{H}$ ), $\mathrm{C}_{60} \mathrm{H}_{26}{ }^{+}$(bis[7] $\left.\mathrm{H} /-8 \mathrm{H}\right)$ and at higher temperatures $\mathrm{C}_{60} \mathrm{H}_{24}{ }^{+}$(bis $[7] \mathrm{H} /-10 \mathrm{H})$ signals are detected. The onset of dehydrogenation coincides with the reduction of the Brintensity (Fig. S4a and c†).

In order to analyse changes in the intensity of the bis[7] $\mathrm{H} /-6 \mathrm{H}$ peak, the fragmentation pattern of bis[7] $\mathrm{H}$ is taken into account (Fig. 3g) in the same way as for $\operatorname{Br}[7] \mathrm{H}$. The intensity of bis[7] $\mathrm{H} /-8 \mathrm{H}$ is not analysed quantitatively, because fragmentation of both bis[7] $\mathrm{H} /-6 \mathrm{H}$ and bis[7] $\mathrm{H}$ would need to be taken into account. Qualitatively it can be said that the intensity of bis[7] $\mathrm{H} /-8 \mathrm{H}$ closely follows the one of bis $[7] \mathrm{H} /-6 \mathrm{H}$. For the same reason, bis[7] $\mathrm{H} /-10 \mathrm{H}$ is analysed only in the temperature ranges where the intensities of signals related to bis[7] $\mathrm{H} /-6 \mathrm{H}$ and bis[7] $\mathrm{H} /-8 \mathrm{H}$ are negligible (Fig. $3 \mathrm{~h}$ ). The species of bis $[7] \mathrm{H} /-10 \mathrm{H}$ appears at higher temperatures than $\operatorname{bis}[7] \mathrm{H} /-6 \mathrm{H}$ and $\operatorname{bis}[7] \mathrm{H} /-8 \mathrm{H}$ and remains the sole specific bis[7] $\mathrm{H}$ product at $695 \mathrm{~K}$ (Fig. 3c). Annealing to $722 \mathrm{~K}$ leads to disappearance of all bis[7]H-related signals (Fig. S4c†). The intensity of the $\mathrm{C}^{-}$signal does not change significantly during these steps (data not shown). Therefore, the loss of specific masses is due to non-specific $\mathrm{C}-\mathrm{C}$ coupling and fragmentation leading to many different products and not due to desorption of significant amounts of carbon.
ToF-SIMS data obtained for a submonolayer coverage $(\approx 0.25$ ML) of solution-synthesized bis[7]H (Fig. S5 $\dagger$ ), compared with $\approx 0.25 \mathrm{ML}$ of $\mathrm{Br}[7] \mathrm{H}$ (Fig. S6†) show no significant differences in the dehydrogenation reactions. This confirms that the presence of $\mathrm{Br}$ does not influence the dehydrogenation process. There are slight differences with respect to the saturated layer of $\operatorname{Br}[7] \mathrm{H}$ : the temperatures for Ullmann coupling, Br desorption (after debromination of $\mathrm{Br}[7] \mathrm{H}$ ) and dehydrogenation reactions are slightly lower. Moreover, the $\mathrm{Br}[7] \mathrm{H}$ spectrum at high coverage exhibits peaks corresponding to $\mathrm{C}_{30} \mathrm{H}_{19} \mathrm{Br}^{+}$, i.e. $\mathrm{Br}[7] \mathrm{H}$ with two additional $\mathrm{H}$ atoms. Since these higher masses are also observed in the non-annealed $\operatorname{Br}[7] \mathrm{H}$ multilayer (Fig. S4 $\uparrow$ ), but not in the dilute submonolayer (Fig. S6†), it is tentatively ascribed to SIMS related hydrogenation during desorption of the secondary ions. ${ }^{37}$

The temperature-induced transformation of dibenzoheptahelicene (DBH, dinaphtho[2,1;1 $\left.1^{\prime}, 2^{\prime}-f_{y}\right]$ picene) on $\mathrm{Ag}(111)$ has been studied in great detail previously by Stetsovych et al. ${ }^{12}$ Planarization of DBH to a dibenzocoronene occurs via DielsAlder cycloaddition and a phenyl group shift at $520 \mathrm{~K}$, followed by dehydrogenation and $\mathrm{C}-\mathrm{C}$ bond formation between phenyl group and the dibenzocoronene unit. Each of these two steps releases $2 \mathrm{H}$ atoms. Starting from bis[7] $\mathrm{H}$ or $\mathrm{Br}[7] \mathrm{H}$, respectively, the discussed reactions predict bis[7] $\mathrm{H} /-\{2,4,6,8,10\} \mathrm{H}$ as possible products (Fig. 1). The Diels-Alder cycloaddition and phenyl group shift of the $7[\mathrm{H}]$ subunit and the $\mathrm{C}-\mathrm{C}$ bonds formed by intramolecular dehydrogenation are exemplified in 
red and blue, respectively. After losing $10 \mathrm{H}$, which is equivalent to formation of 5 new $\mathrm{C}-\mathrm{C}$ bonds, the molecule is completely planar with no possibility for further intramolecular cyclodehydrogenation. The observation of masses corresponding to bis[7] $\mathrm{H} /-\{6,8,10\} \mathrm{H}$ confirms such scenario. Interestingly, bis[7] $\mathrm{H} /-\{2,4\} \mathrm{H}$ was not detected; the first dehydrogenation product is bis[7] $\mathrm{H} /-6 \mathrm{H}$. This may be explained by planarization via Diels-Alder at one helicene subunit, which allows for stronger interaction with the substrate, increasing the driving force for further dehydrogenation. In particular the planar isomers (Fig. 1) are expected to be the most probable bis[7] $\mathrm{H} /-6 \mathrm{H}$ isomers. A side-step in which benzyne and $\mathrm{H}_{2}$ extrusion occurs $(-78 \mathrm{u})^{\mathbf{1 2}}$ is not observed here on $\mathrm{Au}(111)$.

\section{Mechanism of $\mathrm{HBr}$ and $\mathrm{H}_{2}$ desorption}

$\mathrm{HBr}$ and $\mathrm{H}_{2}$ desorption are modelled based on a generalized version of the Polanyi-Wigner equation. ${ }^{\mathbf{3 8 , 3 9}}$ Because the Ullmann coupling occurs well before the dehydrogenation and $\mathrm{HBr}$ desorption steps, the simulation starts with bis[7] $\mathrm{H}$ and $\mathrm{Br}$ rather than $\mathrm{Br}[7] \mathrm{H}$. The rate equations (see ESI $\dagger$ ) explicitly model the coverage of transient atomic $\mathrm{H}\left(\theta_{\mathrm{H}}\right)$. The temperature position of the sudden rise in the $\mathrm{H}_{2}$ TPR spectra with respect to the $\mathrm{H}_{2}$ TPR maxima is determined by the number of bromine atoms with respect to the number of released hydrogen atoms (Fig. S5 $\uparrow$ ). $\mathrm{H}_{2}$ and $\mathrm{HBr}$ TPR spectra simulated with $2 \mathrm{Br}$ atoms per bis[7]H and $6 \mathrm{H}$ atoms produced by dehydrogenation reproduce the temperature of the step quite well (Fig. 3c). The loss of 6 to $10 \mathrm{H}$ per molecule (Fig. S6†) is consistent with the dehydrogenation products identified by ToF-SIMS.

Based on the simulations, the mechanism of $\mathrm{HBr}$ and $\mathrm{H}_{2}$ evolution can be described as follows: because the rate limiting step is the dehydrogenation and the two competing reaction pathways $\left(\mathrm{H}_{2}\right.$ and $\mathrm{HBr}$ desorption) have similarly low activation energies, ${ }^{\mathbf{1 4}}$ any produced atomic $\mathrm{H}$ can immediately react with surface adsorbed $\mathrm{Br}$ and desorbs as $\mathrm{HBr}$ (Fig. 4). This reaction is first order with respect to the coverages of atomic $\mathrm{H}$ and $\mathrm{Br}$ and its rate is proportional to the product of the coverages $\theta_{\mathrm{H}} \times \theta_{\mathrm{Br}}$. The $\mathrm{H}_{2}$ desorption pathway requires collision of two surface adsorbed hydrogen atoms and is therefore a second order process. The rate of $\mathrm{H}_{2}$ desorption is therefore proportional to $\theta_{\mathrm{H}}{ }^{2}$. Because the first process keeps the coverage of transient atomic $\mathrm{H}$ extremely low over a wide range of $\mathrm{Br}$ coverage, the $\mathrm{H}_{2}$

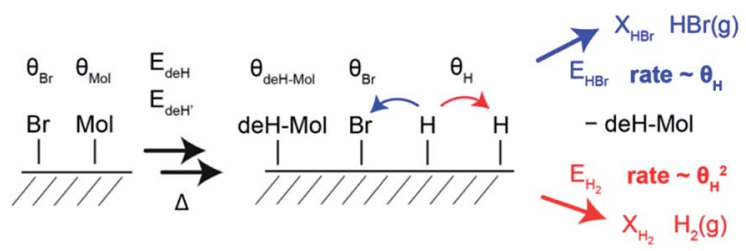

Fig. 4 Sketch of the dehydrogenation reaction inducing $\mathrm{H}_{2}$ and $\mathrm{HBr}$ desorption. In presence of $\mathrm{Br}$, the atomic $\mathrm{H}$ produced by dehydrogenation can either desorb as $\mathrm{H}_{2}$ or $\mathrm{HBr}$. Because the rates of $\mathrm{H}_{2}$ and $\mathrm{Br}$ desorption are much higher than the rate of atomic hydrogen production, the coverage by atomic $\mathrm{H}\left(\theta_{H}\right)$ is very small at any time. Since $\mathrm{HBr}$ desorption is first order with respect to atomic hydrogen and $\mathrm{H}_{2}$ desorption is second order, $\mathrm{H}_{2}$ desorption is strongly disfavoured until $\mathrm{Br}$ has been completely desorbed.

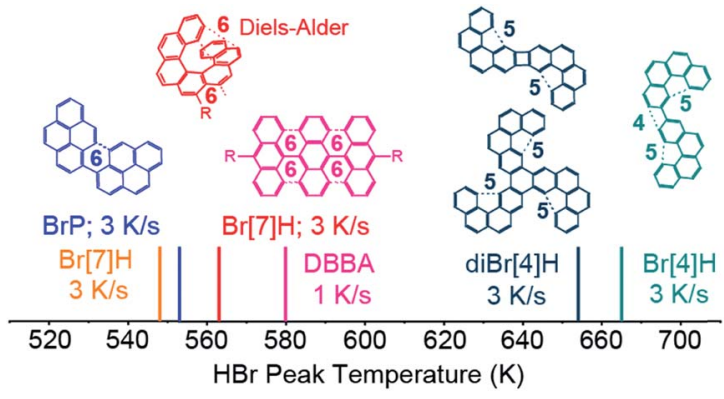

Fig. 5 TPRS $\mathrm{HBr}$ desorption maxima of saturated layers of $\mathrm{BrP}, \mathrm{Br}[7] \mathrm{H}$, DBBA, ${ }^{14} \mathrm{diBr}[4] \mathrm{H}$ and $\mathrm{Br}[4] \mathrm{H}$ on $\mathrm{Au}(111)$. The desorption temperature varies by more than $100 \mathrm{~K}$. The structures of the Ullmann coupling products which are relevant for the dehydrogenation reactions are shown. As indicated by dashed lines, bispyrene, polyanthracene ${ }^{6}$ and bis[7] $\mathrm{H}$ can intramolecularly (cyclo)dehydrogenate to unstrained $\mathrm{C}_{6}{ }^{-}$ rings, while bis[4] and tris[4] helicenes cannot form $C_{6}$ rings, but strained $\mathrm{C}_{4}$ and $\mathrm{C}_{5}$-motifs or undergo possibly other intermolecular $\mathrm{C}-\mathrm{C}$ coupling and dehydrogenation.

desorption is enabled suddenly once the $\mathrm{Br}$ coverage reaches zero, leading to the conspicuous step. At temperatures at which peak $\alpha$ is observed, the $\mathrm{HBr}$ desorption rate is about seven orders of magnitude higher than the rate of dehydrogenation. Therefore, the model is not sensitive for changes of the attempt frequencies and the exact values of the activation energies for $\mathrm{H}_{2}$ and $\mathrm{HBr}$ desorption are not critical. With the expected $\mathrm{H} / \mathrm{Br}$ ratio of 4 , the model used here also reproduces the step of the $\mathrm{H}_{2}$ TPRS of ref. 14 and its temperature position within the $\mathrm{H}_{2}$ desorption peak (Fig. S8†).

\section{General trend for $\mathrm{HBr}$ desorption in presence of different hydrocarbons}

In order to understand why the reported temperatures for $\mathrm{Br}$ desorption vary by more than $100 \mathrm{~K},{ }^{20-25} \mathrm{HBr}$ desorption from saturated monolayers of 1-bromopyrene (BrP), 2,3-dibromo[4] helicene $(\operatorname{diBr}[4] \mathrm{H})$ and 2-bromo[4] helicene $(\mathrm{Br}[4] \mathrm{H})$ on $\mathrm{Au}(111)$ is studied (Fig. 5). The respective TPR spectra are shown in Fig. S9. $\dagger$ The $\mathrm{HBr}$ peak temperature for DBBA on $\mathrm{Au}(111)^{\mathbf{1 4}}$ is also included in Fig. 5. For the different molecules, the $\mathrm{HBr}$ desorption temperatures span from $548 \mathrm{~K}$ to $665 \mathrm{~K}$. For molecules which can form $\mathrm{C}_{6}$-rings (BrP, DBBA and $\mathrm{Br}[7] \mathrm{H}$ ) after on-surface Ullmann coupling, ${ }^{6,26,36} \mathrm{HBr}$ desorbs in the range of 548 to $580 \mathrm{~K}$.

For bis- and tris[4]helicenes obtained by Ullmann coupling of $\mathrm{Br}[4] \mathrm{H}$ and $\operatorname{diBr}[4] \mathrm{H},{ }^{26,36} \mathrm{HBr}$ desorption occurs at $653 \mathrm{~K}$ and 665 K. Here, the possible dehydrogenation products involve the formation of less-favoured 4- or 5-membered rings. At such high temperatures, dehydrogenation by intermolecular $\mathrm{C}-\mathrm{C}$ coupling cannot be excluded. This tentative model qualitatively explains the higher dehydrogenation temperatures of tetrahelicene dimers and trimers with respect to bis-pyrene, bis-heptahelicene and polyanthracene.

\section{Conclusions}

In conclusion, starting from $\mathrm{Br}[7] \mathrm{H}$, the step-wise Ullmann coupling, dehydrogenation and $\mathrm{HBr}$ desorption are studied 
using mass spectrometry. ToF-SIMS reveals the dehydrogenation of bisheptahelicenes losing 6, 8 and $10 \mathrm{H}$ atoms. Such products correspond to a reaction mechanism proposed previously for dibenzoheptahelicene. ${ }^{12}$ Comparison to experiments with $e x$ situ synthesized bis[7] $\mathrm{H}$ as starting material, rather than $\mathrm{Br}[7] \mathrm{H}$, reveals that $\mathrm{Br}$ does not affect the dehydrogenation process. TPRS simulations assuming low activation energies for $\mathrm{HBr}$ and $\mathrm{H}_{2}$ desorption explain the peculiar characteristics of the $\mathrm{HBr}$ and $\mathrm{H}_{2}$ TPR signals. $\mathrm{HBr}$ desorption as a first order reaction with respect to the atomic $\mathrm{H}$ concentration is favoured over the $\mathrm{H}_{2}$ desorption as a second order reaction. Because the dehydrogenation reaction is the rate limiting step, the concentration of atomic $\mathrm{H}$ is extremely low as long as $\mathrm{Br}$ is present. Therefore, $\mathrm{H}_{2}$ desorption is enabled exactly when all $\mathrm{Br}$ is desorbed. Different $\mathrm{HBr}$ desorption temperatures are explained by different dehydrogenation mechanisms of the Ullmann-coupling products of different brominated polycyclic aromatic hydrocarbons. A strong correlation between the structure of the dehydrogenation product and the HBr desorption temperature is found. For molecules for which the formation of $\mathrm{C}_{6}$ rings is possible, $\mathrm{HBr}$ desorption occurs at around 560 $\mathrm{K}$. In the case of molecules allowing only $\mathrm{C}_{4}$ and $\mathrm{C}_{5}$ rings formation or intermolecular dehydrogenation, $\mathrm{HBr}$ desorption at an about $100 \mathrm{~K}$ higher temperature is observed. Consequently, a connection between stereochemistry of hydrocarbons and $\mathrm{HBr}$ desorption temperature is established.

\section{Conflicts of interest}

There are no conflicts to declare.

\section{Acknowledgements}

Financial support by the University Research Priority Program LightChEC of the University of Zürich, Switzerland, the Swiss National Science Foundation (R'Equip, projects 200020_163296 and 173720, CR23I2-162828), and the Competence Centre for Materials (CCMX) is gratefully acknowledged. Financial support in France by the CNRS, the University of Angers and the Région Pays de la Loire through the RFI LUMOMAT (grant to K.M.) is acknowledged.

\section{Notes and references}

1 F. Ullmann and J. Bielecki, Chem. Ber., 1901, 34, 2174-2185. 2 M. Xi and B. E. Bent, J. Am. Chem. Soc., 1993, 115, 7426-7433.

3 L. Grill, M. Dyer, L. Lafferentz, M. Persson, M. V. Peters and

S. Hecht, Nat. Nanotechnol., 2007, 2, 687-691.

4 Q. Fan, J. M. Gottfried and J. Zhu, Acc. Chem. Res., 2015, 48, 2484-2494.

5 M. Bieri, M.-T. Nguyen, O. Gröning, J. Cai, M. Treier, K. AïtMansour, P. Ruffieux, C. A. Pignedoli, D. Passerone, M. Kastler, K. Müllen and R. Fasel, J. Am. Chem. Soc., 2010, 132, 16669-16676.

6 J. Cai, P. Ruffieux, R. Jaafar, M. Bieri, T. Braun, S. Blankenburg, M. Muoth, A. P. Seitsonen, M. Saleh, X. Feng, K. Mullen and R. Fasel, Nature, 2010, 466, 470-473.
7 M. Treier, C. A. Pignedoli, T. Laino, R. Rieger, K. Müllen, D. Passerone and R. Fasel, Nat. Chem., 2011, 3, 61-67.

8 G. Otero, G. Biddau, C. Sánchez-Sánchez, R. Caillard, M. F. López, C. Rogero, F. J. Palomares, N. Cabello, M. A. Basanta, J. Ortega, J. Méndez, A. M. Echavarren, R. Pérez, B. Gómez-Lor and J. A. Martín-Gago, Nature, 2008, 454, 865-868.

9 A. Wiengarten, J. A. Lloyd, K. Seufert, J. Reichert, W. Auwärter, R. Han, D. A. Duncan, F. Allegretti, S. Fischer, S. C. Oh, Ö. Sağlam, L. Jiang, S. Vijayaraghavan, D. Écija, A. C. Papageorgiou and J. V. Barth, Chem.-Eur. J., 2015, 21, 12285-12290.

10 A. Wiengarten, K. Seufert, W. Auwärter, D. Ecija, K. Diller, F. Allegretti, F. Bischoff, S. Fischer, D. A. Duncan, A. C. Papageorgiou, F. Klappenberger, R. G. Acres, T. H. Ngo and J. V. Barth, J. Am. Chem. Soc., 2014, 136, 9346-9354.

11 X. Leng, Y. Lu, G. Feng, Z. Wang, W. Li, X. Liu, R. Zhang, N. Zhang and L. Wang, Chem. Commun., 2017, 53, 91519154.

12 O. Stetsovych, M. Švec, J. Vacek, J. V. Chocholoušová, A. Jančařík, J. Rybáček, K. Kosmider, I. G. Stará, P. Jelínek and I. Starý, Nat. Chem., 2016, 9, 213-218.

13 X.-L. Zhou, J. M. White and B. E. Koel, Surf. Sci., 1989, 218, 201-210.

14 C. Bronner, J. Björk and P. Tegeder, J. Phys. Chem. C, 2015, 119, 486-493.

15 A. Rieger, S. Schnidrig, B. Probst, K.-H. Ernst and C. Wäckerlin, J. Phys. Chem. C, 2017, 121, 27521-27527.

16 M. Röckert, M. Franke, Q. Tariq, D. Lungerich, N. Jux, M. Stark, A. Kaftan, S. Ditze, H. Marbach, M. Laurin, J. Libuda, H.-P. Steinrück and O. Lytken, J. Phys. Chem. C, 2014, 118, 26729-26736.

17 J. Nowakowski, C. Wäckerlin, J. Girovsky, D. Siewert, T. A. Jung and N. Ballav, Chem. Commun., 2013, 49, 23472349.

18 A. Mairena, M. Wienke, K. Martin, N. Avarvari, A. Terfort, K.-H. Ernst and C. Wäckerlin, J. Am. Chem. Soc., 2018, 140, 7705-7709.

19 M. Smerieri, I. Píš, L. Ferrighi, S. Nappini, A. Lusuan, C. Di Valentin, L. Vaghi, A. Papagni, M. Cattelan, S. Agnoli, E. Magnano, F. Bondino and L. Savio, Nanoscale, 2016, 8, 17843-17853.

20 M. Di Giovannantonio, O. Deniz, J. I. Urgel, R. Widmer, T. Dienel, S. Stolz, C. Sánchez-Sánchez, M. Muntwiler, T. Dumslaff, R. Berger, A. Narita, X. Feng, K. Müllen, P. Ruffieux and R. Fasel, ACS Nano, 2018, 12, 74-81.

21 K. A. Simonov, N. A. Vinogradov, A. S. Vinogradov, A. V. Generalov, E. M. Zagrebina, N. Mårtensson, A. A. Cafolla, T. Carpy, J. P. Cunniffe and A. B. Preobrajenski, J. Phys. Chem. C, 2014, 118, 1253212540.

22 T. A. Pham, F. Song, M.-T. Nguyen, Z. Li, F. Studener and M. Stöhr, Chem.-Eur. J., 2016, 22, 5937-5944.

23 A. Batra, D. Cvetko, G. Kladnik, O. Adak, C. Cardoso, A. Ferretti, D. Prezzi, E. Molinari, A. Morgante and L. Venkataraman, Chem. Sci., 2014, 5, 4419-4423. 
24 D. G. de Oteyza, A. García-Lekue, M. Vilas-Varela, N. MerinoDíez, E. Carbonell-Sanromà, M. Corso, G. Vasseur, C. Rogero, E. Guitián, J. I. Pascual, J. E. Ortega, Y. Wakayama and D. Peña, ACS Nano, 2016, 10, 9000-9008.

25 L. Smykalla, P. Shukrynau, M. Korb, H. Lang and M. Hietschold, Nanoscale, 2015, 7, 4234-4241.

26 C. Wäckerlin, J. Li, A. Mairena, K. Martin, N. Avarvari and K.-H. Ernst, Chem. Commun., 2016, 52, 12694-12697.

27 T. Biet, A. Fihey, T. Cauchy, N. Vanthuyne, C. Roussel, J. Crassous and N. Avarvari, Chem.-Eur. J., 2013, 19, 1316013167.

28 A. Sudhakar and T. J. Katz, Tetrahedron Lett., 1986, 27, 22312234.

29 H. Hinzert, K. K. Kleinherbers, E. Janssen and A. Goldmann, Appl. Phys. A: Solids Surf., 1989, 49, 313-320.

30 U. Bardi and G. Rovida, Surf. Sci., 1983, 128, 145-168.

31 T. V. Pavlova, B. V. Andryushechkin and G. M. Zhidomirov, J. Phys. Chem. C, 2016, 120, 2829-2836.
32 J. Björk, F. Hanke and S. Stafström, J. Am. Chem. Soc., 2013, 135, 5768-5775.

33 M. Röckert, M. Franke, Q. Tariq, S. Ditze, M. Stark, P. Uffinger, D. Wechsler, U. Singh, J. Xiao, H. Marbach, H.-P. Steinrück and O. Lytken, Chem.-Eur. J., 2014, 20, 8948-8953.

34 J. Eichhorn, T. Strunskus, A. Rastgoo-Lahrood, D. Samanta, M. Schmittel and M. Lackinger, Chem. Commun., 2014, 50, 7680 .

35 L. Dong, P. N. Liu and N. Lin, Acc. Chem. Res., 2015, 48, 27652774.

36 J. Li, K. Martin, N. Avarvari, C. Wäckerlin and K.-H. Ernst, Chem. Commun., 2018, 54, 7948-7951.

37 ToF-SIMS: materials analysis by mass spectrometry, ed. J. C. Vickerman and D. Briggs, SurfaceSpectra Limited, Manchester, 2nd edn, 2013.

38 P. A. Redhead, Vacuum, 1962, 12, 203-211.

39 A. M. de Jong and J. W. Niemantsverdriet, Surf. Sci., 1990, 233, 355-365. 